\title{
Indoor air pollution exposure effects on lung and cardiovascular health in the High Himalayas, Nepal: An observational study
}

\author{
Lorenza Pratali $^{\mathrm{a}, 1}$, Angela Marinoni ${ }^{\mathrm{b}, 1}$, Annalisa Cogo ${ }^{\mathrm{c}, 1}$, Kristian Ujka ${ }^{\mathrm{a}}$, Stefania Gilardoni ${ }^{\mathrm{b}}$, \\ Eva Bernardi ${ }^{\mathrm{c}}$, Paolo Bonasoni ${ }^{\mathrm{b}}$, Rosa Maria Bruno ${ }^{\mathrm{a}, \mathrm{e}}$, Luca Bastiani ${ }^{\mathrm{a}}$, Elisa Vuillermoz ${ }^{\mathrm{d}}$, \\ Paolo Sdringola ${ }^{\mathrm{f}}$, Sandro Fuzzi ${ }^{\mathrm{b} \text {, }}$ \\ ${ }^{a}$ Institute of Clinical Physiology, National Research Council, Pisa, Italy \\ ${ }^{\mathrm{b}}$ Institute of Atmospheric Sciences and Climate, National Research Council, Bologna, Italy \\ ${ }^{\mathrm{c}}$ Biomedical Sport Studies Center, University of Ferrara, Ferrara, Italy \\ ${ }^{\mathrm{d}}$ EvK2CNR Committee, Bergamo, Italy \\ ${ }^{\mathrm{e}}$ Department of Clinical and Experimental Medicine, University of Pisa, Pisa, Italy \\ ${ }_{\mathrm{f}}^{\mathrm{f}}$ Department of Engineering, University of Perugia, Perugia, Italy
}

\section{A R T I C L E I N F O}

\section{Keywords:}

Particulate matter

Cardiovascular disease

Respiratory disease

Indoor air pollution

Black carbon

Himalayas.

\begin{abstract}
A B S T R A C T
Background: Exposure to indoor biomass fuel smoke is associated with increased morbidity and mortality. The aim of this study is to evaluate the association between exposure to indoor biomass burning and early pulmonary and cardiovascular damage.

Methods: The indoor levels of particulate matter (PM) $\left[\mathrm{PM}_{10}, \mathrm{PM}_{2.5}\right]$ and black carbon (BC) were monitored in 32 houses in a Himalayan village. Seventy-eight subjects were submitted to spirometry and cardiovascular evaluation [carotid to femoral pulse wave velocity (PWV) and echocardiography].

Results: Peak indoor BC concentration up to $100 \mu \mathrm{g} \mathrm{m}^{-3}$ and $\mathrm{PM}_{10}-\mathrm{PM}_{2.5}$ up to $1945-592 \mu \mathrm{m} \mathrm{m}^{-3}$ were measured. We found a non-reversible bronchial obstruction in $18 \%$ of subjects $\geq 40 \mathrm{yr}$; mean forced expiratory flow between $25 \%$ and $75 \%$ of the forced vital capacity $\left(\mathrm{FEF}_{25-75}\right)<80 \%$ in $54 \%$ of subjects, suggestive of early respiratory impairment, significantly and inversely related to age. Average BC was correlated with right ventricular-right atrium gradient $(R=0.449, p=.002)$, total peripheral resistances (TPR) $(R=0.313, p=.029)$ and PWV $(R=0.589, p<.0001)$ especially in subjects $>30$ yr. In multiple variable analysis, BC remained an independent predictor of PWV $(\beta=0.556, p=.001)$, and TPR $(\beta=0.366 ; p=.018)$.

Conclusions: Indoor pollution exposure is associated to early pulmonary and cardiovascular damages, more evident for longer duration and higher intensity exposure.
\end{abstract}

\section{Introduction}

According to the World Health Organization (WHO), indoor air pollution (IAP) is the single most important environmental health risk factor worldwide. Based on estimates of solid fuel use for cooking in 2012, exposure to air pollution causes 4.3 million premature deaths each year, with the highest burden in low and middle-income countries [1]. More specifically, particulate matter (PM) is considered to be associated with an increased incidence of cardiovascular and respiratory diseases [2,3]. In particular, the black carbon (BC) component of PM seems to be associated with both cardiovascular and respiratory morbidity and mortality $[4,5]$. Specifically, the incomplete combustion of solid fuels is a source of potentially toxic pollutants, including BC, carbon monoxide, nitrogen dioxide, volatile and semi-volatile organic compounds (e.g., formaldehyde and benzo[a]pyrene, methylene chloride, and dioxins).

However, only a limited number of studies have focused the attention on the concurrent effects of IAP on cardiovascular and

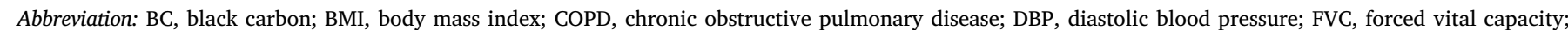

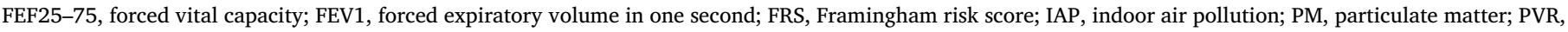

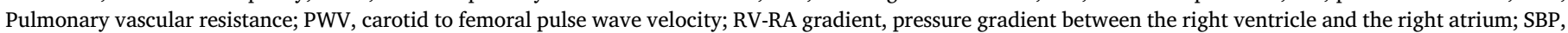
systolic blood pressure; sPAP, systolic pulmonary artery pressure; TPR, total peripheral resistances; WHO, World Health Organization

* Corresponding author at: Institute of Atmospheric Sciences, National Research Council, Bologna, Italy.

E-mail address: s.fuzzi@isac.cnr.it (S. Fuzzi).

${ }^{1}$ These authors contributed equally to this work. 
respiratory diseases [6]. IAP from biomass fuel and coal combustion in open fires and traditional stoves causes $>2$ million deaths per year in large areas of the less developed world [6,7], and can be considered a major avoidable risk factor for respiratory and cardiac diseases $[7,8]$. According to the most recent WHO report on non-communicable diseases, $35 \%$ of chronic obstructive pulmonary disease (COPD) could be prevented through a healthy indoor environment [9].

The aim of our study is to evaluate the presence of an association between IAP exposure and early impairment of respiratory function, COPD prevalence and cardiovascular damages in a population with a very low smoking habit, living in a rural village of a remote area far from any road and vehicular traffic and also far from other specific anthropogenic sources of pollution.

\section{Methods}

\subsection{Chaurikharka: the ideal village to study}

The study was conducted in the traditional village of Chaurikharka (2562 m.a.s.1.), in the Khumbu Valley (Nepalese Himalayas) (supplementary fig. 1) where the Sherpa population lives isolated from the most common sources of outdoor pollution [10]. Because of cultural and religious traditions, the Sherpa have a very low smoke habit (only $3 \%)^{9 ;}$ morover other medical confounding factors (obesity and diabetes) are rare $[11,12]$. The households still rely on solid fuels (wood, crop residues, dung) for cooking and other energy needs. In addition, these solid fuels are often burned in inefficient, poorly ventilated combustion devices: such as open fires and traditional stoves [13] (supplementary fig. 2).

\subsection{Population enrolled}

A total of 78 villagers, living in the 32 houses submitted to IAP monitoring, were enrolled for the medical tests.. Inclusion criteria were: age between 16 and 75 years, residential status in the village, apparent good health status and written informed consent. Exclusion criteria were: alcohol abuse, active neoplasm, infective diseases, pregnancy and the absence of informed consent. A structured interview in Nepalese language was performed to collect data on smoking habits, job, stove characteristics, cooking details, and history of fuel use in their households. Indoor and outdoor air quality measurements were acquired during two field campaigns during winter 2013/14 and 2014/15. This study follows the Declaration of Helsinki on medical protocol and was conducted with the approval of the Nepal Health Research Council and the Nepal Academy of Science and Technology ( $\left.N^{\circ} 115 / 2013\right)$, and registered to Clinical Trials Gov Registration \#NCT01329159.

\subsection{Indoor pollution measurements}

IAP was measured in the houses enrolled using a portable monitoring unit developed ad hoc for the Chaurikharka experiment to monitor BC, PM mass, and size distribution. The monitoring unit was installed for about $24 \mathrm{~h}$ to obtain the diurnal trend of the different measured parameters. Indoor PM with aerodynamic diameter lower than $10 \mu \mathrm{m}\left(\mathrm{PM}_{10}\right)$ and lower than $2,5 \mu \mathrm{m}\left(\mathrm{PM}_{2,5}\right)$, as well as $\mathrm{BC}$ concentrations were measured. In addition, the outdoor air was monitored over the same period to have a reference parameter for the IAP measurements, and to evaluate the indoor/outdoor exchanges. Full methods on the IAP measurements and device characteristics are available on supplementary file 1 .

\subsection{Medical tests}

\subsubsection{Laboratory tests}

Out of 78 subjects enrolled, 55 accepted to perform fasting blood samples for laboratory tests. Lipid profile, electrolytes and blood glucose were all determined in order to discriminate between the role of IAP and the role of other cardiovascular risk factors. The glomerular filtration rate was estimated using the Modification of Diet in Renal Disease study equation [14].

\subsubsection{Pulmonary function tests}

All 78 participants underwent spirometry using a portable spirometer at their household in a sitting position, in fire-off conditions, in accordance with the American Thoracic Society/European Respiratory Society guidelines [15]. Before the test, height and weight were measured. Two experts in respiratory functions (A.C. and E.B.) assessed the quality of the spirometry and the best of three reproducible values was used in the data analysis. In the presence of airflow obstruction, Salbutamol was administered in four separate doses of $100 \mu \mathrm{g}$ through a spacer, re-assessing lung function after fifteen minutes. An increase in forced expiratory volume in one second $\left(\mathrm{FEV}_{1}\right)$ of $12 \%$ and $200 \mathrm{~mL}$ constitutes a positive bronchodilator response. The airflow obstruction is defined when the ratio of $\mathrm{FEV}_{1}$ to forced vital capacity (FVC) is below the 5 th percentile of the predicted value, to minimise over- or underdiagnosis $[16,17]$. The normal reference values were taken from the European Community of Coal and Steel [17] prediction equations. Chronic bronchitis is defined as the presence of both chronic cough and chronic phlegm for at least three months and for two consecutive years. The COPD is defined as the presence of non-reversible bronchial obstruction, according to the GOLD guidelines. Early respiratory function impairment is defined as a reduction of the mean forced expiratory flow between $25 \%$ and $75 \%$ of the FVC $\left(\mathrm{FEF}_{25-75}\right)$ below $80 \%$ of the predicted value [15].

\subsubsection{Physiological parameters and cardiovascular evaluation}

Out of 78 subjects (mean age $41 \pm 16$, female 51), enrolled, 72 accepted to perform also the cardiovascular evaluation (55 of these performed also laboratory test). The cardiovascular evaluation was performed in dedicated laboratory without any IAP source and was carried out between 9 a.m. and 4 p.m. Brachial systolic (SBP) and diastolic blood pressure (DBP) were measured in supine position after at least 10 - min rest. Three measurements at 2-min intervals were taken, and averaged over the last two measurements. Finger oxygen saturation, weight, height, and waist circumference were also measured and the body mass index (BMI) was calculated. The 10-year Framingham risk score (FRS) for cardiovascular events was calculated according to the guidelines [18].

Carotid-femoral pulse wave velocity (PWV) was measured by applanation tonometry (Sphygmocor CVPH, Atcor Medical, Sidney, Australia), according to the international recommendations [19]. Waveforms were recorded at the two recording sites, sequentially with simultaneous electrocardiogram. PWV was calculated as the ratio between the subtracted distance between the two recording sites [(femoral-suprasternal distance) - (carotid-suprasternal distance)] and wave transit time (estimated by the foot-to-method). Two consecutive measurements were taken and averaged.

Echocardiography was performed using a portable echo machine with a cardiac probe $(2.5-3.5 \mathrm{MHz})$. The left ventricular systolic and diastolic measures were performed according to the ASE-EAE guidelines [20-21-22]. The pressure gradient between the right ventricle and the right atrium (RV-RA gradient) was calculated using the modified Bernoulli equation from the maximal velocity of continuous Doppler tricuspid regurgitation and the systolic pulmonary artery pressure (SPAP) was estimated on the basis of inferior vena cava size and its respiratory variations $(0-15 \mathrm{mmHg}$ ) [23]. Pulmonary vascular resistance (PVR) was calculated as [(mean PAP-left atrial pressure)/Cardiac Output] [24].

\subsection{Statistical analysis}

The statistical analysis was performed using the SPSS software, version 21.0 (IBM Corp., Armonk, NY, USA). Statistical significance for 
all tests used was set at $p<.05$. Clinical, pulmonary and cardiovascular characteristics of the samples were assessed using descriptive statistics and comparison of the different parameters between sex was performed by unpaired Student $t$-test. Pearson's rho correlation analysis was carried out to compare markers of pulmonary and cardiovascular damage and different air pollutants and to evaluate the effect of IAP on lung function. The significant correlations were then included in two different multiple regression models. First model: to evaluate the relation between vascular markers (PWV and TPR) and IAP (PM/BC) independently from covariates (age, sex, oxygen saturation, SBP, low density lipoproteins). Second model: to evaluate the relation between early pulmonary impairment $\left(\mathrm{FEF}_{25-75}\right)$ and IAP (PM/BC) independently from covariates (age, sex, smoking habit). Before the multiple regression model analysis, covariates were individually tested using univariate linear regression models. Smoking was not included in both models because of the low smoking prevalence. Before the multiple regression model analysis, covariates were individually tested using univariate linear regression models. Multi-collinearity between variables was also assessed.

\section{Results}

\subsection{Indoor particulate measurements}

The indoor average $\mathrm{BC}$ concentration and the average PM mass in different size ranges $\left(\mathrm{PM}_{2.5}\right.$ and $\left.\mathrm{PM}_{10}\right)$ are reported in Fig. 1 for the 32 monitored households. The overall average indoor $\mathrm{BC}$ concentration was $4.63 \pm 6.61 \mu \mathrm{g} \mathrm{m}^{-3}$, (range: $0.31-36.540 .31 \mu \mathrm{g} \mathrm{m}^{-3}$ ). On the other hand, $\mathrm{PM}_{2.5}$ and $\mathrm{PM}_{10}$ average concentrations were $35 \pm 24 \mu \mathrm{g} \mathrm{m}^{-3}$ (range: $1-648 \mu \mathrm{g} \mathrm{m}^{-3}$ ) and $113 \pm 64 \mu \mathrm{g} \mathrm{m}^{-3}$ (range: $1 \mu \mathrm{g} \mathrm{m}^{-3}$ to $1945 \mu \mathrm{g} \mathrm{m}^{-3}$ ), respectively.

We observed a large fraction of coarse particle mass, with $\mathrm{PM}_{2.5}$ accounting, on average, for $33 \%$ of $\mathrm{PM}_{10}$. This is probably due to the handling of the embers when the fire is on and to re-suspended dust within the houses. The typical diurnal trends generally exhibit BC peaks up to $100 \mu \mathrm{g} \mathrm{m}^{-3}$ and $\mathrm{PM}_{10}$ and $\mathrm{PM}_{2.5}$ peaks of $1945 \mu \mathrm{g} \mathrm{m}^{-3}$ and $592 \mu \mathrm{g} \mathrm{m}^{-3}$, respectively, regularly taking place in the evenings and mornings, when the fire is turned on for cooking dinner and breakfast/lunch. An example of the $24 \mathrm{~h}$ monitoring of the house identified as CHH13 is reported in Fig. 2.

The average fire duration was between 6:00 and 9:00 a.m.) and between 4:00 and 8:00 p.m. with a nocturnal minima (averages of $0.32 \pm 0.39 ; 11.5 \pm 29.2$ and $26.5 \pm 63.1 \mu \mathrm{g} \mathrm{m}^{-3}$, for $\mathrm{BC} \mathrm{PM}_{2.5}$ and $\mathrm{PM}_{10}$ concentrations, respectively) that were close to the outdoor concentrations, suggesting a significant exchange between indoor and outdoor air. The typical increase of concentrations during cooking time was about 40 times for $\mathrm{BC}$ and 10 times for $\mathrm{PM}_{2.5}$ and $\mathrm{PM}_{10}$ values with respect to the night-time conditions.

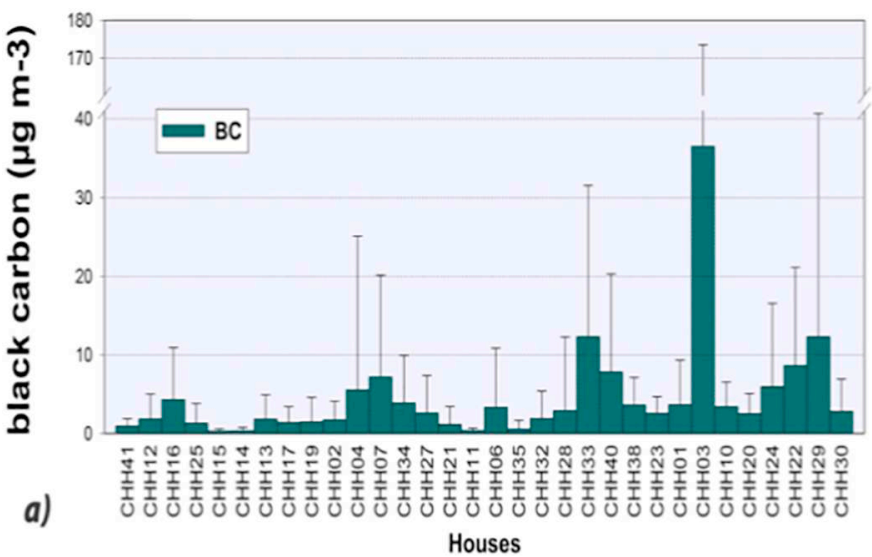

\section{House CHH13}

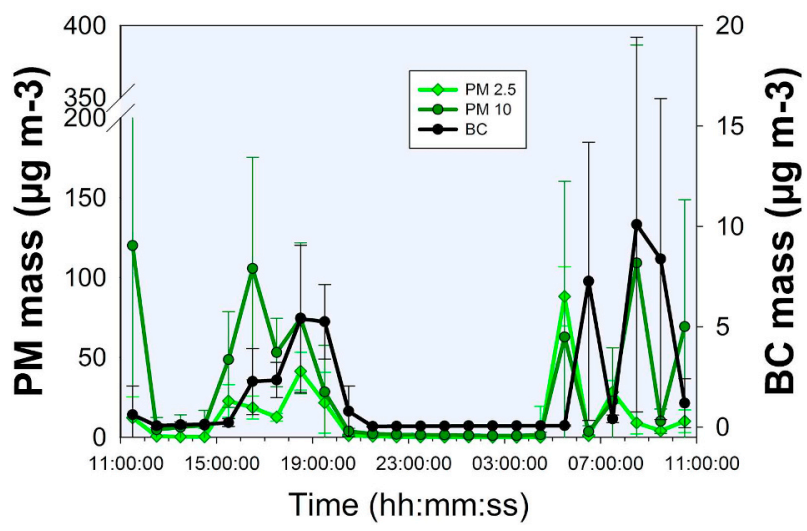

Fig. 2. $\mathrm{BC}, \mathrm{PM}_{2.5}$ and $\mathrm{PM}_{10}$ concentrations monitored in the house $\mathrm{CHH} 13$. Error bars represent the standard deviation of the measurements.

The $\mathrm{BC}$ concentration accounts on average for $9 \%$ of the $\mathrm{PM}_{2.5}$ mass, with a significant increase during the periods when the fire was on (12\% on average, with a maximum of $42 \%$ on an hourly basis), while during night-time the $\mathrm{BC}$ mass was stable around $5 \%$ of that of $\mathrm{PM}_{2.5}$.

On the other hand, the $\mathrm{PM}_{2.5} / \mathrm{PM}_{10}$ ratio was higher during nighttime (45\%) with respect to the fire-on conditions (35\%), suggesting a slow settling of coarse particles such as fly ashes and re-suspended dust when the fire was off.

The outdoor average concentrations were lower by a factor of about 6 for both $\mathrm{BC}$ and PM concentration with respect to the indoor average values. The ratio between indoor and outdoor concentrations was similar for the different aerosol fractions and for $\mathrm{BC}$ (5.7 for $\mathrm{PM}_{2.5}, 6.5$ for $\mathrm{PM}_{10}$ and 6.4 for $\mathrm{BC}$ ), suggesting that the main source for the local outdoor pollution in Chaurikharka is the indoor biomass combustion itself. An example of outdoor monitoring is shown in supplementary fig. 3.

\subsection{Clinical results}

The population was not normally distributed: in fact, 50 out of 78 subjects enrolled in the study (64\%) were younger than 40 years.

\subsubsection{Pulmonary evaluation}

Supplementary table 1 reports the demographic and pulmonary function data. As we didn't find any difference between males and females, in the subsequent analysis we considered the group as a whole. Six subjects (all non-smokers) showed bronchial obstruction; 4 females

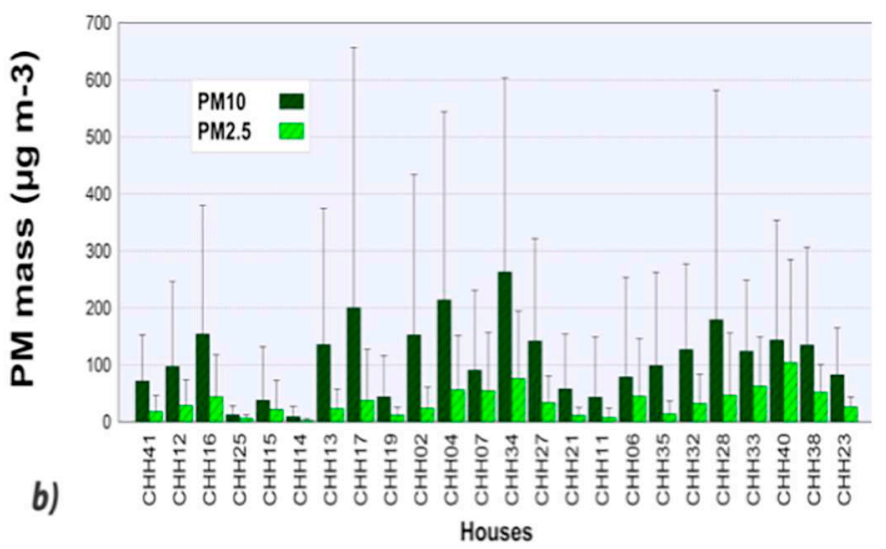

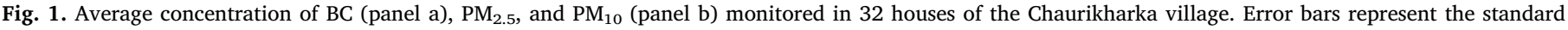
deviation of the measurements. 
Table 1

Correlation between pulmonary function and indoor air particulate concentrations.

\begin{tabular}{llll}
\hline & $\mathrm{PM}_{2.5}$ & $\mathrm{PM}_{10}$ & $\mathrm{BC}$ \\
\hline $\mathrm{FEV}_{1}$ /FVC (\%) & $R=-0.12$ & $R=-0.213$ & $R=-0.031$ \\
& $p=.506$ & $p=.234$ & $p=.608$ \\
& $N=33$ & $N=33$ & $N=54$ \\
$\mathrm{FEV}_{1}(\%)$ & $R=-0.023$ & $R=-0.044$ & $R=-0.063$ \\
& $p=.898$ & $p=.81$ & $p=.65$ \\
& $\mathrm{~N}=33$ & $\mathrm{~N}=33$ & \\
$\mathrm{FEF}_{25-75}(\%)$ & $R=-0.243$ & $R=-0.413$ & $R=55$ \\
& $p=.173$ & $p=.017$ & $\mathrm{p}=.608$ \\
& $\mathrm{~N}=33$ & $\mathrm{~N}=33$ & $\mathrm{~N}=54$ \\
\hline
\end{tabular}

$\mathrm{FEV}_{1}$ : expiratory volume in the first second; FVC: forced vital capacity; $\mathrm{FEF}_{25-75}$ : flow in the middle part of the expiration curve.

and 2 males aged 45-85 years. In one female we found a significant reversibility, allowing diagnosing her simply as asthmatic, while in the other five subjects no significant reversibility was detected and the diagnosis of COPD was made. The prevalence of non-reversible bronchial obstruction was 5/78 (6\%). The prevalence of COPD was higher in subjects $\geq 40$ years group and is infrequent at younger age. Taking into account only subjects aged $\geq 40$ years, the prevalence is $18 \%$, rising to $20 \%$ considering only the subjects over the age of 50 .

We found that only 36 out of 78 subjects exhibited normal values of $\mathrm{FEF}_{25-75}$, (i.e. $\geq 80 \%$ of the predicted values), 9 subjects had a value between 70 and $80 \%, 33$ subjects had a value $\leq 70 \%$. A significant linear regression was found between $\mathrm{FEF}_{25-75} \%$ (percentage of the predicted values) and age (supplementary fig. 4). $\mathrm{FEF}_{25-75} \%$ was significantly correlated with the average $\mathrm{PM}_{10}$ concentration $(r=-$ 0.413, $p=.017$ ) (Table 1).

In a multiple regression analysis including age, sex, and average $\mathrm{PM}_{10}$, only age and average $\mathrm{PM}_{10}$ concentration remained independent predictors of the reduction of respiratory function $\left(\mathrm{FEF}_{25-75} \%\right)$ $(p<.001$ and $p=.001$, respectively). Full model results are shown in Table 2.

No significant correlation was found between the markers of respiratory and cardiovascular damage (data not shown).

\subsubsection{Cardiovascular and laboratory test evaluation}

Seventy-two out of 78 subjects enrolled accepted the cardiovascular evaluation and out of 72 subjects, 55 were submitted also to the blood samples and laboratory tests. Supplementary table 2 summarises the clinical characteristics and laboratory results of the population examined. Overall, the examined population was young, but the prevalence of hypertension and hypercholesterolemia were relatively high, while diabetes, obesity and smoking habit were low. The blood level of cholesterol (total, low and high density lipoproteins) was slightly above normal, while triglycerides and glucose concentration were normal. Oxygen saturation and haemoglobin concentration were compatible with a good acclimatization to altitude. Moreover the creatinine concentration and the estimated glomerular filtration rate were also normal. The 10-year FRS, evaluated for 42 subjects (age 30-75 years), was $4.9 \%(3.2-8.97 \%)$.

PWV was successfully performed in 63 subjects related to technical

Table 2

Multiple regression analysis between $\mathrm{FEF}_{25-75} \%$ and age, sex, smoking history and indoor pollution concentrations.

\begin{tabular}{llll}
\hline & Variable & $\beta$ & $P$ value \\
\hline Variable: $\mathrm{FEF}_{25-75}(\%)$ & Age & $-\mathbf{0 . 6 2 0}$ & $<\mathbf{0 . 0 0 1}$ \\
Full model & Sex & 0.148 & 0.273 \\
$R=0.724$ & Average $\mathrm{PM}_{10}$ & $-\mathbf{0 . 4 9 9}$ & $\mathbf{0 . 0 0 1}$ \\
\hline
\end{tabular}

$\mathrm{FEF}_{25-75}$ : flow in the middle part of the expiration curve. problems. Mean PWV was $7.2 \pm 1.6 \mathrm{~m} \mathrm{~s}^{-1}$. FRS and PWV were significantly correlated with the average BC concentrations $(R=0.414$, $p=.017$ and $R=0.398 ; p=.002$; Table 3 ). Including in the analysis only people older than 30 years who, we can reasonably assume, had been exposed continuously and for a longer time period to indoor biomass burning emissions, the association became stronger for PWV $(R=0.589, p<.0001)$. In addition, BC peak concentration correlates well with both FRS and PWV $(R=0.56, p=.009$ and $R=0.445$, $p=.001)$. In a multiple variable analysis, the average BC concentration remained an independent predictor of PWV, even after adjusting data for age, sex, systolic BP and low density lipoprotein concentration ( $\beta=0.556, \mathrm{p}=.001$; full model $R=0.734$; Table 4 ), indicating that long-term exposure to indoor biomass burning pollution may be associated with subclinical cardiovascular damage independent of classical cardiovascular risk factors. The principal echocardiographic indexes are reported in supplementary table 3 . The subjects exhibited normal left and right systolic and diastolic function. Only sPAP, PVR and TPR were slightly above normal in the population examined. RV-RA gradient significantly correlated with average BC concentration $(R=0.293$; $p=.22$ ) while a low, yet significant, correlation was found between total TPR and $\mathrm{BC}$ average concentration $(R=0.277 ; p=.037)$. After excluding subjects younger than 30 (considering them to a have a shorter lifespan IAP exposure), the correlation with average BC concentration became stronger with the RV-RA gradient $(R=0.449$, $p=.002)$ and TPR $(R=0.313 ; p=.029)$, while a significant positive correlation was found between TPR and $\mathrm{PM}_{10}$ average concentration $(R=0.359 ; p=.044)$.

Furthermore, a negative correlation was found between SV and average BC concentration $(R=-0.337 ; p=.024)$, as shown in Table 3. From multiple regression analysis, TPR remained correlated with $\mathrm{BC}$ average concentration even after adjustment for age, SBP and oxygen saturation $(\beta=0.366 ; p=.018$; full model $R=0.542$ ), as shown in Table 4.

\section{Discussion}

The analysis of the combined measurements of indoor PM and BC levels together with the results of pulmonary and cardiovascular tests for the inhabitants of this traditional Himalayan village showed early pulmonary and cardiovascular damage, which become more evident with the duration and the intensity of exposure to IAP. No significant correlation was found between the markers of respiratory and cardiovascular damage. The individual susceptibility to the diseases can explain the lack of association in the same subjects of the first signs of both respiratory and cardiovascular impairment [25]. In fact, the inhalation of pollutants has different effects on the cardiovascular and respiratory functions. Air pollution can have either a very rapid effect on vascular dysfunction, indicative of pathways that convey signals within hours of PM inhalation or chronic effects promoting atherosclerosis' mediators [2]. On the contrary, air pollution adversely affects the lung function through structural and inflammatory changes and the long-term exposure to noxious particles is associated with early impairment as well as non-reversible chronic obstruction. A short exposure mainly affects bronchial hyper-responsiveness that has not been assessed in the present study. This explains why the cardiovascular damage is significantly related with both PM and BC indoor concentrations, while the early respiratory impairment is significantly related only to the level of $\mathrm{PM}_{10}$ particles. The pulmonary and cardiovascular detrimental effects due to IAP were evident although the number of hours of combustion activity observed were slightly lower than that reported in a study carried out in Eastern Tibetan Plateau $(8.9 \mathrm{~h})$ [26], and those reported from WHO in selected studies of rural areas [9], likely due to the lack of fire activity in the central part of the day. In any case, the values monitored during this study were much higher than the WHO interim and guideline values [1,27]. On the other hand, the indoor $\mathrm{BC}$ average values are lower than those reported for 
Table 3

Correlation analysis between average and peak BC and cardiovascular parameters.

\begin{tabular}{|c|c|c|c|c|c|c|}
\hline \multirow[t]{2}{*}{ Pearson correlations } & \multirow[t]{2}{*}{$\mathrm{PM}_{2.5}$} & \multirow[t]{2}{*}{$\mathrm{PM}_{10}$} & \multirow[t]{2}{*}{ BC } & $\mathrm{PM}_{2.5}$ & $\mathrm{PM}_{10}$ & BC \\
\hline & & & & (Only age > 30) & (Only age > 30) & (Only age $>30$ ) \\
\hline \multirow[t]{3}{*}{ FRS* } & & & & $R=0.021$ & $R=-0.063$ & $R=0.414$ \\
\hline & & & & $p=.925$ & $p=.774$ & $p=.017$ \\
\hline & & & & $\mathrm{N}=23$ & $N=23$ & $\mathrm{~N}=33$ \\
\hline \multirow[t]{3}{*}{ PWV } & $R=0.079$ & $\mathrm{R}=-0.023$ & $\mathrm{R}=0.398$ & $R=0.066$ & $R=0.108$ & $\mathrm{R}=0.589$ \\
\hline & $p=.654$ & $P=.895$ & $\mathrm{p}=.002$ & $p=.729$ & $P=.569$ & $\mathrm{p}<.0001$ \\
\hline & $N=35$ & $\mathrm{~N}=35$ & $N=57$ & $\mathrm{~N}=30$ & $N=30$ & $N=45$ \\
\hline \multirow{3}{*}{ RV-RA gradient } & $R=0.206$ & $R=0.067$ & $\mathrm{R}=0.293$ & $R=0.188$ & $\mathrm{R}=0.108$ & $\mathrm{R}=0.313$ \\
\hline & $p=.208$ & $p=.685$ & $p=.022$ & $P=.287$ & $\begin{array}{l}p=.545 \\
\text { N34 }\end{array}$ & $p=.029$ \\
\hline & $\mathrm{N}=39$ & $N=39$ & $N=61$ & $N=34$ & & $N=49$ \\
\hline \multirow[t]{3}{*}{ TPR } & $R=0.134$ & $R=0.269$ & $\mathrm{R}=0.589$ & $R=0.161$ & $R=0.359$ & $R=0.449$ \\
\hline & $P=.430$ & $P=.108$ & $\mathrm{p}=.037$ & $p=.379$ & $\mathrm{p}=.044$ & $\mathrm{p}=.002$ \\
\hline & $\mathrm{N}=37$ & $N=37$ & $\mathrm{~N}=57$ & $N=32$ & $\mathrm{~N}=32$ & $\mathrm{~N}=45$ \\
\hline \multirow[t]{3}{*}{ SV } & $R=-0.115$ & $R=-0.247$ & $R=0.051$ & $R=-0.209$ & $R=-0.325$ & $\mathrm{R}=-0.337$ \\
\hline & $P=.499$ & $P=.140$ & $p=.714$ & $p=.252$ & $p=.070$ & $p=.024$ \\
\hline & $\mathrm{N}=37$ & $\mathrm{~N}=37$ & $N=53$ & $\mathrm{~N}=32$ & $\mathrm{~N}=32$ & $N=45$ \\
\hline
\end{tabular}

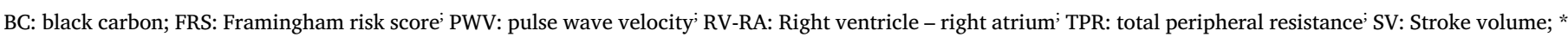
FRS was calculated only for the subjects aged over 30 years.

Table 4

Multiple variable correlation models between PWV, TPR and BC concentration.

\begin{tabular}{llll}
\hline & Variable & $\beta$ & P value \\
\hline Variable & Age & 0.271 & 0.105 \\
PWV & Sex & 0.119 & 0.40 \\
Full model & Systolic blood pressure & 0.072 & 0.64 \\
$R=0.734$ & LDL & -0.017 & 0.90 \\
& BC average concentration & 0.556 & 0.001 \\
Variable TPR & Age & -0.09 & 0.526 \\
Full model & Oxygen saturation & 0.155 & 0.259 \\
R $=0.542$ & Systolic blood pressure & 0.279 & 0.070 \\
& BC average concentration & 0.404 & 0.008 \\
\hline
\end{tabular}

PWV: pulse wave velocity; TPR: total peripheral resistance; LDL: Low density lipoprotein; BC: black carbon.

villages of Northern India by Kar et al. [28], where measurements were performed only in fire-on conditions; however the cooking peaks measured in the present study were comparable with the measurements performed in the breathing zone $(1 \mathrm{~m}$ above the stove and $0.5 \mathrm{~m}$ on the side) in dwellings where wood is burned in traditional stoves [28].

From the respiratory tests, we found a high percentage of subjects with reduced peripheral flow $\left(\mathrm{FEF}_{25-75}\right)$ and non-reversible bronchial obstruction, characteristic of COPD. The reduction of the flow in the middle part of expiration is considered an early impairment of the respiratory function. In fact, the earliest change associated with airflow obstruction is a slowing of the expiratory flow, reflected in a proportionally higher reduction in $\mathrm{FEF}_{25-75}$ than in $\mathrm{FEV}_{1}$. As the airway disease becomes more advanced and more central airways become involved, the $\mathrm{FEV}_{1}$ will be reduced out of proportion to the reduction in $\mathrm{VC}$ and the ratio $\mathrm{FEV}_{1} / \mathrm{FVC}$ decreases [29]. A reduction in $\mathrm{FEF}_{25-75}$ has been reported in smokers [30], but also in non-smokers chronically exposed to tobacco smoke [31], and in subjects with occupational and environmental exposures [32]. White et al. also found that exposed non-smokers had a lower forced mid-expiratory flow with respect to non-exposed non-smokers [31].

Since $64 \%$ of the subjects examined in the present study were younger than 40 years, we could hypothesize in advance that an early impairment of the respiratory function would have been the main finding. In fact, we found a high prevalence of $\mathrm{FEF}_{25-75}$ reduction below $80 \%$ of the predicted values. An intriguing finding of our study is the significant correlation between $\mathrm{FEF}_{25-75}$ as a percentage of predicted and age. In fact, the predicted values already take into account the effect of aging and the decreasing values (compared to the predicted ones) with age reflect the effect of continuous exposure to high levels of noxious particles. This is confirmed by the correlation of $\mathrm{FEF}_{25-75}$ with indoor $\mathrm{PM}_{10}$ concentration. Similarly we can interpret the progressive reduction of the ratio $\mathrm{FEV}_{1} / \mathrm{FVC}$ with exposure to IAP. It has recently been suggested that biomass smoke may contribute to the onset of respiratory diseases by fostering a pulmonary and systemic inflammatory state, and the first effect of chronic inflammation is the structural change and narrowing of the small airways [33]. The onset of non-fully reversible airflow obstruction (COPD) is a slow, gradual process and only a longitudinal study could assess the progression of early impairment to COPD.

There is an increasing amount of evidence of a high incidence of chronic bronchitis, respiratory function impairment and COPD among people exposed to high levels of IAP, PM in particular [4,34]. With respect to the prevalence of COPD, it is well known that a variable percentage of COPD-affected subjects have never smoked but have been exposed since childhood to inhalation of noxious particles. In fact, in developing countries, indoor/outdoor air pollution and poor socioeconomic status play an important role in the pathogenesis of nonsmoking-related COPD $[35,36]$. Furthermore, it has been shown that the children of mothers using biomass fuel for cooking and heating have a lower weight at birth than those whose mothers used other energy sources [37]. This fact, associated to the higher incidence of respiratory infection in the childhood of the exposed subjects, can predispose an individual to developing COPD in the adulthood. Any factor that affects lung growth during gestation and childhood has the potential for increasing an individual's risk of developing COPD. Many surveys on COPD in never-smokers have reported that a history of hospitalization in childhood for respiratory illness and exposure to passive smoke or biomass fuel were discriminative for children and women, respectively [38-42]. All studies available in the literature examined the prevalence of the disease in population aged 40 and older with a reported prevalence among never-smokers between 3 and 11\% [43]. In the present study, we found a prevalence of COPD among never-smokers aged 40 years and older of $18 \%$, higher than the previously reported values. In developed countries a higher prevalence of chronic bronchitis and COPD is shown generally in men, instead in the rural areas of developing countries, the prevalence is either similar between men and women or much higher in women, even in the case of very limited or no smoking habit [44]. Norboo and coauthors showed in a Himalayan village a prevalence of COPD in subjects over 50 years of $24 \%$ in men and $32 \%$ in women [45]. Moreover the relative risk for COPD in subjects over 30 years exposed to IAP has been found to be 3.2 in women 
and 1.8 in men [46]. The higher COPD prevalence in women and children was associated to longer time near the fireplace, especially during the winter months in the mountain regions [47-50]. Surprisingly, in the present study we did not find any difference of COPD prevalence between females and males. We explain this result because females in this area are mainly farmers working outside and most of the dwellers (both males and females) spend the night in the same room of the brazier. Therefore, the length of exposure would not be significantly different.

The cardiovascular evaluation has shown an association between BC exposure and subclinical cardiovascular damage in particular, in longtime exposed subjects older than 30 years. Moreover, BC concentration was significantly correlated with the RV-RA gradient and TPR and, again, these correlations were stronger in subjects older than 30 years. In a multivariate analysis, the 24-h average indoor BC concentration was an independent predictor for PWV and TPR, even after adjustment for possible confounding factors: age, sex, SBP and low density lipoproteins for PWV and age, SBP and oxygen saturation for TPR. The measurement of aortic stiffness as carotid-femoral PWV by arterial tonometry, is a well-known subclinical marker of cardiovascular damage that can serve in the clinical practice as "intermediate" or "surrogate" endpoint for cardiovascular events and cardiovascular mortality, beyond the classic cardiovascular risk factors [19,51]. The correlation between PWV and BC suggests that long-term exposure to $\mathrm{BC}$ and other air pollutants accelerate atherosclerosis and induce vascular damage increasing the risk of cardiovascular morbidity and mortality. On the other hand, the correlation between BC and the RV-RA gradient, although in the absence of any significant RV dysfunction, may indicate a tendency to increased pulmonary pressure in subjects exposed to IAP. Noteworthy in the multiple regression analysis, TPR remained correlated with $\mathrm{BC}$ average concentration even after adjustment for age, SBP and oxygen saturation.

The cardiovascular findings are in agreement with previous studies showing higher risk of cardiovascular diseases in subjects exposed to IAP. A 10-year cohort study in Bangladesh showed an increased risk of cardiopulmonary death in populations using solid fuel compared to those using gas fuel [52], while two large-scale cohort studies conducted in China and in Pakistan showed that IAP due to solid fuel use is associated with an increased risk of coronary heart disease and acute coronary syndrome, with a higher risk in subjects over 40 years [53,54]. Many studies have shown increasing risk for hypertension development in subjects exposed to IAP and in some studies an improvement after interventions on the chimney of the stoves was shown [55,56]. Furthermore, a cross-sectional study of Indian women evidenced that hypertension had a prevalence of $30 \%$ among biomass fuel users, and of only $11 \%$ among liquid gas users [56]. The prevalence odd ratio risk for hypertension was 1.41 times higher for women experiencing indoor fine PM concentration levels above the median of the study population. In addition, women older than 50 years appear to have a higher risk of hypertension compared to men. In addition, a recent study conducted in Shanghai, China, showed that IAP increases the risk of hypertension but also demonstrated that the effect is reversible reducing the exposure to indoor PM [58].

\subsection{Strengths and limitations of the study}

In most published studies on the health effects of indoor biomass smoke the enrolled subjects were usually also exposed to cigarette smoke and/or outdoor environmental pollution. In the present study, the monitored outdoor pollution was low and similar for the entire population living in the small village, isolated from the most common sources of pollution. In addition, the other confounding factors were also very low in the population sample examined.

Some limitations of the study should also be acknowledged. First: the indoor air quality measurements initiated during the winter 2013 campaign, were completed only in winter 2014/2015, due to instrumental failure. To ensure a uniformity of the monitored conditions between the two campaigns, a lifestyle habits and household procedures questionnaire survey was performed. Second: lack of followup evaluation after interventions on the chimney of the stoves. A follow up study was hypothesized after 2 years but failed due to the 2015 Nepal earthquake that destroyed also Chaurikharka.

\section{Conclusions}

This study confirms that indoor air pollution due to biomass smoke in inefficient stoves and in the absence of stove chimney is deleterious and induces a significant early impairment of airways function and subclinical cardiovascular damage. Moreover, a long term PM and BC exposure, as in the case of the older subjects enrolled, was associated to substantial burden of COPD and of cardiovascular dysfunction. Simple interventions supporting the use of clean cook stoves and fuels these communities could dramatically reduce indoor combustion emissions and the resulting exposure and adverse health effects.

\section{Declaration of interest}

None.

\section{Acknowledgment}

This work was carried out within the Ev-K2-CNR SHARE (Stations at High Altitude for Research on the Environment) project. The authors would like to thank Dr. Buddha Basnyat, Dr. Bikash Basyal and Dr. Sanjeeb Sundarshan Bhandari, who were involved in recruiting subjects for the study and in helping for the respiratory and cardiovascular tests. Thanks are also due to Laxman Adhikary, Tenzing Chhottar Sherpa, Lhakpa Tshering Sherpa, Lakpa Tenzi Sherpa and Gian Pietro Verza for their technical support during the field campaigns.

The Ev-K2-CNR Association works in collaboration with the Italian National Research Council to promote technological and scientific research at high altitude, particularly in the Hindu Kush-KarakorumHimalaya region. The Association's mission concerns the improvement of living conditions for local population and the scientific support for sustainable development in high altitude areas. Publication fees were provided by Ferrara University. The funding bodies played no role in any aspect of the study (study design; data collection, analysis, or interpretation; or writing of the manuscript).

\section{Appendix A. Supplementary data}

Supplementary data to this article can be found online at https:// doi.org/10.1016/j.ejim.2018.10.023.

\section{References}

[1] WHO Burning Opportunity: Clean Household Energy for Health. Sustainable development, and wellbeing of women and children. http://apps.who.int/iris/ bitstream/10665/204717/1/9789241565233_eng.pdf?ua=1; 2016 (Accessed March 1 2018).

[2] Brook RD, Rajagopalan S, Pope CA, et al. Particulate matter air pollution and cardiovascular disease: an update to the scientific statement from the American Heart Association. Circulation 2010;121(21):2331-78.

[3] Pope CA, Dockery DW. Health effects of fine particulate air pollution: lines that connect. J Air Waste Manag 2006;56(6):709-42.

[4] Gordon SB, Bruce NG, Grigg J, et al. Respiratory risks from household air pollution in low and middle income countries. Lancet Respir Med 2014;2(10):823-60.

[5] Janssen NAH, Gerlofs-Nijland ME, Lanki T, et al. Health effects of black carbon. WHO Reports; 2012http://www.euro.who.int/_data/assets/pdf_file/0004/ 162535/e96541.pdf Accessed March 12018.

[6] Bruce N, Smith KR. WHO indoor air quality guidelines: household fuel combustion. http://www.who.int/indoorair/guidelines/hhfc/Review_4.pdf; 2014 Accessed March 12018.

[7] Mortimer K, Gordon SB, Jindal SK, et al. Household air pollution is a major avoidable risk factor for cardiorespiratory disease. Chest 2012;142(5):1308-15.

[8] Kurmi OP, Ayres JG. The non-occupational environment and the lung: opportunities 
for intervention. Chron Respir Dis 2007;4(4):227-36.

[9] Riley L, Cowan M. Non communicable diseases progress monitor. World Health Organization; 2015. . ISBN: 9789241509459.

[10] Bonasoni P, Laj P, Marinoni A, et al. Jatmospheric brown clouds in the himalayas: First two years of continuous observations at the Nepal Climate observatory-pyramid (5079 m) Atmos. Chem Phys 2010;10:7515-31.

[11] Subedi YP, Marais D, Newlands D. Where is Nepal in the nutrition transition? Asia Pac J Clin Nutr 2017 Mar;26(2):358-67.

[12] Lhamo SY, Supamai S, Virasakdi C. Impaired glucose regulation in a Sherpa indigenous population living in the Everest region of Nepal and in Kathmandu Valley. High Alt Med Biol 2008 Fall;9(3):217-22.

[13] Duo E, Bruno RM, Basnyat B, et al. Indoor pollution in high-altitude dwellings: An assessment of affecting factors across four Sherpa villages in the Khumbu region, Nepal. Indoor Build Environ 2016;0/(0):1-10.

[14] Levey AS, Bosch JP, Lewis JB, et al. A more accurate method to estimate glomerular filtration rate from serum creatinine: a new prediction equation. Modification of diet in renal disease study group. Ann Intern Med 1999;130:461-70.

[15] Miller MR, Hankinson J, Brusasco V, et al. Standardisation of spirometry. Eur Respir J 2005;26:319-38.

[16] Quanjer PH, Stanojevic S, Cole TJ, et al. Multi-ethnic reference values for spirometry for the 3-95-yr age range: the global lung function 2012 equations. Eur Respir J 2012;40(6):1324-43.

[17] Gibson GJ. Standardized lung function testing. Eur Respir J 1993;16:25-7.

[18] D'Agostino RB, Vasan RS, Pencina MJ, et al. General cardiovascular risk profile for use in primary care: The framingham heart study. Circulation 2008;117:743-53.

[19] Laurent S, Cockcroft J, Van Bortel L, et al. 2006 Expert consensus document on arterial stiffness: Methodological issues and clinical applications. Eur Heart J 2006;27(21):2588-605.

[20] Lang RM, Badano LP, Mor-Avi V, et al. Recommendations for cardiac chamber quantification by echocardiography in adults: An update from the American society of Echocardiography and the European association of Cardiovascular imaging. J Am Soc Echocardiogr 2015;28(1):1-39. e14.

[21] Quinones MA, Otto CM, Stoddard M, et al. Recommendations for quantification of Doppler echocardiography: A report from the Doppler quantification task force of the nomenclature and standards committee of the American society of echocardiography. J Am Soc Echocardiogr 2002;15(2):167-84.

[22] Nagueh SF, Middleton KJ, Kopelen HA, et al. Doppler tissue imaging: a noninvasive technique for evaluation of left ventricular relaxation and estimation of filling pressures. J Am Coll Cardiol 1997;30(6):1527-33.

[23] Rudski LG, Lai WW, Afilalo J, et al. Guidelines for the echocardiographic assessment of the right heart in adults: a report from the American society of echocardiography endorsed by the European association of echocardiography, a registered branch of the European society of cardiology, and the Canadian society of echocardiography. J Am Soc Echocardiogr 2010;23(7):685-713.

[24] Argiento P, Vanderpool RR, Mule M, et al. Exercise stress echocardiography of the pulmonary circulation: Limits of normal and gender differences. Chest 2012 Nov;142(5):1158-65.

[25] Obeidat M, Hao K, Bossé Y, et al. Molecular mechanisms underlying variations in lung function: a systems genetics analysis. Lancet Respir Med 2015;3(10):782-95.

[26] Carter E, Archer-Nicholls S, Ni K, et al. Seasonal and diurnal air pollution from residential cooking and space heating in the Eastern Tibetan Plateau. Environ Sci Technol 2016;50(15):8353-61.

[27] Clarck ML, Peel JL, Balakrishnan K, et al. Health and household air pollution from solid fuel use: The need for improved exposure assessment. Environ Health Perspect 2013;121(10):1120-8.

[28] Kar A, Rehman IH, Burney J, Puppala SP. Real-time assessment of Black Carbon pollution in Indian households due to traditional and improved biomass cookstoves. Environ Sci Technol 2012;46:2993-3000.

[29] Pellegrino R, Viegi G, Brusasco V, et al. Interpretative strategies for lung function tests. Eur Respir J 2005;26(5):948-68.

[30] Woolf CR. Clinical findings, sputum examinations, and pulmonary function tests related to the smoking habit of 500 women. Chest 1974;66(6):652-9.

[31] White JR, Froeb HF. Small-airways dysfunction in non-smokers chronically exposed to tobacco smoke. N Engl J Med 1980;27(302(13)):720-3.

[32] De Jong D, Boezen HM, Kromhout H, et al. Occupational exposure to vapors, gases, dusts, and fumes is Associated with small airways obstruction. Am J Respir Crit Care Med 2014;2014(189):487-90.

[33] Silva R, Oyarzún M, Olloquequi J. Pathogenic mechanisms in chronic obstructive pulmonary disease due to biomass smoke exposure. Arch Bronconeumol 2015;51(6):285-92.

[34] Kurmi OP, Semple S, Simkhada P, et al. COPD and chronic bronchitis risk of indoor air pollution from solid fuel: A systematic review and meta-analysis. Thorax 2010;65(3):221-8.

[35] Zeng G, Sun B, Zhong N. Non-smoking-related chronic obstructive pulmonary disease: A neglected entity. Respirology 2012;17:908-12.

[36] Peña VS, Miravitlles M, Gabriel R, et al. Geographic variations in prevalence and under diagnosis of COPD: Results of the IBERPOC multicentre epidemiological study. Chest 2000;118:981-9.

[37] Epstein MB, Bates MN, Arora NK, et al. Household fuels, low birth weight, and neonatal death in India: The separate impacts of biomass, kerosene, and coal. Int $J$ Hyg Environ Health 2013;216:523-32.

[38] Atsou K, Chouaid C, Hejblum G. Variability of the chronic obstructive pulmonary disease key epidemiological data in Europe: Systematic review. BMC Med 2011;9:7.

[39] Bischoff EW, Schermer TR, Bor H, et al. Trends in COPD prevalence and exacerbation rates in Dutch primary care. Br J Gen Pract 2009;59(569):927-33.

[40] Rycroft CE, Heyes A, Lanza L, Becker K. Epidemiology of chronic obstructive pulmonary disease: A literature review. Int J Chron Obstruct Pulmon Dis 2012;7:457-94.

[41] Tan WC, Sin DD, Bourbeau J, et al. Characteristics of COPD in never-smokers and ever-smokers in the general population: Results from the CanCOLD study. Thorax 2015;70(9):822-9.

[42] Terzikhan N, Verhamme KM, Hofman A, et al. Prevalence and incidence of COPD in smokers and non-smokers: the Rotterdam study. Eur J Epidemiol 2016;31(8):785-92.

[43] Buist AS, McBurnie MA, Vollmer WM, et al. International variation in the prevalence of COPD (the BOLD Study): A population-based prevalence study. Lancet 2007;370:741-50.

[44] Albalak R, Frisancho AR, Keeler GJ. Domestic biomass fuel combustion and chronic bronchitis in two rural Bolivian villages. Thorax 1999;54:1004-8.

[45] Norboo T, Yahya M, Bruce NG, et al. Domestic pollution and respiratory illness in a Himalayan village. Int J Epidemiol 1991;20(3):749-57.

[46] Rehfuess E. Fuel for life: Household energy and health. World Health Organization; 2006http://www.who.int/indoorair/publications/fuelforlife.pdf Accessed March 1, 2018.

[47] Kurmi OP, Lam KB, Ayres JG. Indoor air pollution and the lung in low- and mediumincome countries. Eur Respir J 2012;40(1):239-54.

[48] Kurmi OP, Semple S, Devereux GS, et al. The effect of exposure to biomass smoke on respiratory symptoms in adult rural and urban Nepalese populations. Environ Health 2014;13:92.

[49] Kankaria A, Nongkynrih B, Gupta SK. Indoor air pollution in India: Implications on health and its control. Indian J Community Med 2014 Oct-Dec;39(4):203-7.

[50] Smith KR, Mehta S, Maeusezahl-Feuz M. Indoor air pollution from household use of solid fuels. Chapter 18:1435-1495. Comparative Quantification of Health Risks. 2004.

[51] Vlachopoulos C, Aznaouridis K, O'Rourke MF, et al. Prediction of cardiovascular events and all-cause mortality with central haemodynamics: a systematic review and meta-analysis. Eur Heart J 2010;31:1865-71.

[52] Alam DS, Chowdhury MAH, Siddiquee AT, et al. Adult cardiopulmonary mortality and indoor air pollution. Glob Heart 2012;7(3):215-21.

[53] Fatmi Z, Coggon D, Kazi A, et al. Solid fuel use is a major risk factor for acute coronary syndromes among rural women: a matched case control study. Public Health 2014;128(1):77-82.

[54] Lee MS, Hang JQ, Zhang FY, et al. In-home solid fuel use and cardiovascular disease: a cross-sectional analysis of the Shanghai Putuo study. Environ Health 2012;11:18.

[55] McCracken JP, Smith KR, Diaz A, et al. Chimney stove intervention to reduce longterm wood smoke exposure lowers blood pressure among Guatemalan women. Environ Health Perspect 2007;115(7):996-1001.

[56] Dutta A, Mukherjee B, Das D, et al. Hypertension with elevated levels of oxidized low-density lipoprotein and anticardiolipin antibody in the circulation of premenopausal Indian women chronically exposed to biomass smoke during cooking. Indoor Air 2011;21(2):165-76.

[58] Chen R, Zhao A, Chen H, et al. Cardiopulmonary benefits of reducing indoor particles of outdoor origin: a randomized, double-blind crossover trial of air purifiers. $J$ Am Coll Cardiol 2015;65(21):2279-87. 